\title{
Unveiling the Molecular Signature of Salivary Gland Neoplasms with Tumor-specific Fusion Oncogenes
}

Fusion oncogenes (FOs) resulting from chromosomal translocations are linked to the initiation and progression of several human cancers including benign and malignant salivary gland neoplasms. ${ }^{1}$ The FO may encode for novel fusion proteins or ectopically expressed normal protein. Studies demonstrating FO in healthy individuals, indicate that the mere presence of FO does not merit tumor formation. ${ }^{2-4}$ Several additional factors shift the balance in favor of tumorigenesis. These include the rate of FO formation, degree of penetrance (potential of the individual FO to induce tumor), susceptibility of the tissue/cells and finally other genetic and epigenetic alterations. Double-strand breaks (DSBs) represent the first stage in the formation of fusion oncogenes as most of the DSBs do not undergo DNA repair. Currently, there is no collaborating evidence for any physiologic event causing FO. External factors including ionizing radiation are documented to be the primary cause of DSBs in leukemias and thyroid cancer. Since most of the benign and malignant salivary gland tumors have radiation as one of their etiologic factors, it is safe to presume that DNBs could be a common event in salivary gland neoplasms. ${ }^{1-4}$

Nordkvist et al and Persson et $\mathrm{al}^{6}$ have shown a recurrent $\mathrm{t}(6 ; 9)(\mathrm{q} 22-23 ; \mathrm{p} 23-24)$ translocation in adenoid cystic carcinoma (ACC). This translocation has in most cases led to the fusion of transcription factor gene NFIB and MYB oncogene. ${ }^{5,6}$ Brill et $\mathrm{al}^{7}$ and West et $\mathrm{al}^{8}$ noticed MYB-NFIB FO was specific for ACC and was not detected in other benign or malignant salivary gland neoplasms. Nordkvist el at elicited a characteristic t(11;19)(q21-22;p13) translocation causing fusion of transcriptional coactivators MAML2 and CRTC1 in salivary, bronchial, and thyroid glands mucoepidermoid carcinoma (MEC) ${ }^{10} \mathrm{CGH}$ study on MEC have shown that the presence of MAML2 and CRTC1 FO has a impact on the overall prognosis. Jee et $\mathrm{al}^{11}$ subdivided MEC into three groups based on the presence or absecnce of FO: (1) FO positive tumors: low grade, favorable prognosis with no, or few genomic imbalances, (2) FO positive tumors: high grade, unfavorable prognosis with multiple genomic imbalances, (3) FO negative nonMEC adenocarcinomas: unfavorable outcome with multiple genomic imbalances. ${ }^{11}$ Enlund et al ${ }^{12}$ demonstrated CRTC1-MAML2 gene fusion in few cases of Warthin's tumor. Winnes et $\mathrm{al}^{13} \mathrm{Fehr} \mathrm{el} \mathrm{al}^{14}$ suggested that the presence of the CRTC1-MAML2 oncogene could represent either the metaplastic variants of Warthin tumors or the possibility of malignant transformation to MEC or may even represent a misdiagnosed case of MEC. Moller et al noticed a repetitive EWSR1-POU5F1 gene fusion due to $\mathrm{t}(6 ; 22)(\mathrm{p} 21 ; \mathrm{q} 12)$ translocation in high grade MECs. ${ }^{15}$

FO due to their tumor specificity may also serve as a diagnostic biomarker especially for rare salivary gland neoplasms. Hyalinizing clear cell carcinoma (HCCC) has similar morphology to clear cell variants of epithelialmyoepithelial carcinoma, myoepithelial carcinoma or MEC. Demonstrating the HCCC specific EWSR1-ATF1 FO will serve as a diagnostic biomarker. ${ }^{16}$ ETV6-NTRK3 gene fusion has been demonstrated in more than $90 \%$ of mammary analogue secretory carcinoma of salivary glands distinguishing it from cell carcinoma and low-grade cystadenocarcinoma. ${ }^{17,18}$ PLAG1 and HMGA2 fusion noticed in most cases of pleomorphic adenoma may serve to distinguish it from diagnostically challenging differentials including adenoid cystic carcinoma, polymorphous low-grade adenocarcinoma. ${ }^{19,20}$ Several cases of carcinoma-ex-pleomorphic adenoma have also shown PLAG1 and HMGA2 fusion in addition to other genetic alterations. ${ }^{21}$

Surgical resection is the primary treatment protocol for salivary gland neoplasms. Treatment for patients presenting with advanced invasion, multiple recurrence, or distant metastasis is mostly palliative in nature as there are no definitive treatment modalities for the same. Studies focussing in disclosing the unique tumor specific FOs may serve as diagnostic biomarkers. The targets for these fusion oncogenes have been responsive to treatment modalities, emphasizing its role in targeted therapy. Unveiling the molecular signatures may also aid to elucidate the pathogenesis behind the difference in aggressiveness among tumors of the same histopathological subtype.

\section{REFERENCES}

1. G*oran Stenman. Fusion oncogenes and tumor type specificity-insights from salivary gland tumors. Seminars in Cancer Biology,2005:224-235

2. Go ran Stenman. Fusion Oncogenes in Salivary Gland Tumors: Molecular and Clinical Consequence. Head and Neck Pathol, 2013; 7:S12-S19

3. Bhaijee F, Pepper DJ, Karen T. Pitman, Diana Bell, Feriyl Bhaijee, Pepper DJ, Pitman KT, Bell D. New developments in the molecular pathogenesis of head and neck tumors: a review of tumor-specific fusion oncogenes in mucoepidermoid carcinoma, adenoid cystic carcinoma, and NUT midline carcinoma. Annals of Diagnostic Pathology, 2011:69-77

4. Pierre $A^{\circ}$ man. Fusion oncogenes in tumor development. Seminars in Cancer Biology, 2005:236-243 
5. Nordkvist A, Mark J, Gustafsson H, Bang G, Stenman G. Non-random chromosome rearrangements in adenoid cystic carcinoma of the salivary glands. Genes Chromosomes Cancer, 1994(10):115-121.

6. Persson M, Andre'n Y, Mark J, Horlings HM, Persson F, Stenman G. Recurrent fusion of MYB and NFIB transcription factor genes in carcinomas of the breast and head and neck. Proc Natl Acad Sci USA. 2009;106:187:40-44.

7. Brill LB, Kanner WA, Fehr A, Andrén Y, Moskaluk CA, Löning T, Stenman G, Frierson Jr HF. Analysis of MYB Expression and MYB-NFIB gene fusions in adenoid cystic carcinoma and other salivary neoplasms. Mod Pathol. 2011;24:11:69-76.

8. West RB, Kong C, Clarke N, Gilks T, Lipsick JS, Cao H, Kwok S, Montgomery KD, Varma S, Le QT. MYB expression and translocation in adenoid cystic carcinoma and other salivary gland tumors with clinicopathological correlation. Am J Surg Pathol. 2011;35:92-99.

9. Nordkvist A, Gustafsson H, Juberg-Ode M, Stenman G. Recurrent rearrangements of 11q14-22 in mucoepidermoid carcinoma. Cancer Genet Cytogenet. 1994;74:77-83.

10. Tonon G, Modi S, Wu L, Kubo A, Coxon AB, Komiya T, O’Neil K, Stover K, El-Naggar A, Griffin JD, Kirsch IR, Kaye FJ. t(11;19) (q21;p13) translocation in mucoepidermoid carcinoma creates a novel fusion product that disrupts a Notch signalling pathway. Nat Genet. 2003;33:208-213.

11. Jee KJ, Persson M, Heikinheimo K, Passador-Santos F, Aro K, Knuutila S, Odell EW, Ma“kitie A, Sundelin K, Stenman G, Leivo I. Genomic profiles and CRTC1-MAML2 fusion distinguish different subtypes of mucoepidermoid carcinoma. Mod Pathol. Sep 2012;28:154. doi:10.1038/modpathol.

12. Enlund F, Behboudi A, Andren Y, O” berg C, Lendahl U, Mark J, Stenman G. Altered Notch signaling resulting from expression of a WAMTP1-MAML2 gene fusion in mucoepidermoid carcinomas and benign Warthin's tumors. Exp Cell Res. 2004;292:21-28.

13. Winnes M, Enlund F, Mark J, Stenman G. The MECT1-MAML2 gene fusion and benign Warthin0s tumour: is the MECT1- MAML2 gene fusion specific to mucoepidermoid carcinoma? J Mol Diagn. 2006;8:394-5. 42.

14. Fehr A, Ro“ser K, Belge G, Lo“ning T, Bullerdiek J. A closer look at warthin tumors and the t(11;19). Cancer Genet Cytogenet. 2008; 180:135-139.

15. Mo“ller E, Stenman G, Mandahl N, Hamberg H, Mo“lne L, van den Oord JJ, Brosjo“ O, Mertens F, Panagopoulos I. POU5F1, encoding a key regulator of stem cell pluripotency, is fused to EWSR1 in hidradenoma of the skin and mucoepidermoid carcinoma of the salivary glands. J Pathol. 2008;215:78-86.

16. Antonescu CR, Katabi N, Zhang L, Sung YS, Seethala RR, Jordan RC, Perez-Ordoñez B, Have C, Asa SL, Leong IT, Bradley G, Klieb H, Weinreb I. EWSR1-ATF1 fusion is a novel and consistent finding in hyalinizing cler-cell sarcoma of salivary gland. Genes Chromosomes Cancer. 2011;50:559-570.

17. Fehr A, Lo"ning T, Stenman G. Mammary analogue secretory carcinoma of the salivary glands with ETV6-NTRK3 gene fusion. Am J Surg Pathol. 2011;35:1600-1602.

18. Tognon C, Knezevich SR, Huntsman D, Roskelley CD, Melnyk N, Mathers JA, Becker L, Carneiro F, MacPherson N, Horsman D, Poremba C, Sorensen PH. Expression of the ETV6-NTRK3 gene fusion as a primary event in human secretory breast carcinoma. Cancer Cell. 2002;2:367-376.

19. Kas K, Voz ML, Ro“ijer E, A ${ }^{\circ}$ stro“m AK, Meyen E, Stenman G, Van de VenWJ. Promoter swapping between the genes for a novel zinc finger protein and beta-catenin in pleiomorphic adenomas with $t(3 ; 8)(p 21 ; q 12)$ translocations. Nat Genet. 1997;15:170-174.

20. Geurts JM, Schoenmakers EF, Ro“ijer E, A ${ }^{\circ}$ stro“m AK, Stenman G, van de Ven WJ. Identification of NFIB as recurrent translocation partner gene of HMGIC in pleomorphic adenomas. Oncogene. 1998;16:865-872.

21. Persson F, Andrén Y, Winnes M, Wedell B, Nordkvist A, Gudnadottir G, Dahlenfors R, Sjo gren H, Mark J, Stenman G. Highresolution genomic profiling of adenomas and carcinomas of the salivary glands reveals amplification, rearrangement, and fusion of HMGA2. Genes Chromosomes Cancer. 2009;48:69-82

Shankargouda Patil

Associate Professor

Department of Oral Pathology and Microbiology Faculty of Dental Sciences, MS Ramaiah University of Applied Sciences Bengaluru, Karnataka, India

Roopa Rao

Professor and Head

Department of Oral Pathology

Faculty of Dental Sciences

MS Ramaiah University of Applied Sciences

Bengaluru, Karnataka, India

Thirumal Raj

Final Year Postgraduate Student

Department of Oral Pathology

Faculty of Dental Sciences

M S Ramaiah University of Applied Sciences

Bengaluru, Karnataka, India 